\title{
Lactancia materna en pediatría
}

En las últimas décadas se ha estado observando una declinación en la frecuencia y duración del amamantamiento tanto en países desarrollados como en países de escaso desarrollo ${ }^{(1,2,3,4)}$. Las razones de este fenómeno son variadas y no serán objeto de análisis en la presente comunicación, salvo aquella que dice relación con la siguiente pregunta: A la luz de la información científica de que actualmente se dispone, ¿se justifica alimentar al pecho a un lactante?

La presente comunicación tiene por objetivo resumir la información acumulada hasta el presente tanto a nivel nacional como internacional en relación a ventajas de la alimentación al pecho. No pretendemos ser exhaustivos, ya que nueva información se está acumulando a diario, por lo que estimamos que el tema merece ser revisado con cierta periodicidad.

Con el objeto de clasificar las ventajas de la alimentación al pecho que aparecen citadas, se estudiaron los efectos de la alimentación al pecho sobre:

1. Crecimiento y Desarrollo.

2. Morbilidad y Mortalidad.

\section{CRECIMIENTO Y DESARROLLO}

Existen estudios en que se ha comparado el aumento de peso, talla y perímetro cefálico de lactantes alimentados al pecho y lactantes alimentados en forma artificial. Harfouche $e^{(5)}$ señala que los lactantes alimentados al pecho aumentan de peso en forma comparable a los lactantes alimentados artificialmente hasta los 3 a 4 meses, siempre que el aporte de ambos casos sea suficiente. El aumento de peso posterior sería superior en los lactantes alimentados en forma artificial, lo que podría no representar ninguna

* Jefie de Programa Infantil Area Hospitalaria Norte ventaja si se asocia a obesidad, cuya incidencia sería superior en el lactante alimentado en forma artificial. Jelliffe ${ }^{(6)}$ señala que el crecimiento y desarrollo del lactante alimentado al pecho es óptimo.

En nuestro medio se han hecho estudios comparando el crecimiento en peso y talla de dos grupos poblaciones, $\left.{ }^{(7,} 8,9\right)$ uno con lactancia prolongada y otro con lactancia corta, encontrándose que mientras en el grupo con lactancia prolongada no se detectan casos de déficit severos de peso, talla o perímetro cefálico, en los alimentados en forma artificial entre el 20 y el $37 \%$ tiene déficit de peso, talla o perímetro cefálico, que los ubica al año bajo el percentil 10 de IOWA. Un estudio reciente, en un medio socioeconómico homogéneo urbano de clase ba$\mathrm{ja}^{(9)}$, ha revelado que el estado nutritivo a los 6 meses de lactantes alimentados al pecho es superior al de los no alimentados al pecho. Así los que reciben pecho se ubican todos sobre el percentil 3 de IOWA, en tanto que de los que no reciben pecho en forma exclusiva un $16 \%$ se ubica bajo el percentil 3 de IOWA.

\section{MORBILIDAD Y MORTALIDAD}

De acuerdo a Harfouche ${ }^{(5)}$, el lactante alimentado al pecho tiende a tener sus primeras enfermedades más tarde y además éstas son menos numerosas y más benignas. Con esta aseveración están de acuerdo de una u otra manera la totalidad de los autores revisados.

¿En qué evidencias científicas se basa lo anterior?

Grulee $^{(10)}$ estudió hacia 1934 un total de 20.061 lactantes, de los cuales una proporción (9.749) recibió pecho exclusivo por 9 meses, otra proporción recibió pecho en forma parcial (8.605) y un tercer grupo recibió alimentación artificial 
consistente en leche de vaca hervida, diluida con agregado de azúcar (1.707). Al comparar la incidencia de infecciones intestinales, respiratorias y otras no clasificadas entre los tres grupos, se observó que ellas eran menores en los lactantes alimentados al pecho. La tasa de mortalidad infantil, que era de $1.5 \%$ en los que se amamantaban, subía a $84.7 \%$, en los que sólo recibían alimentación artificial. La mortalidad por infecciones intestinales era de $0.2 \%$ en los alimentados en forma natural y de $8 \%$ en los con alimentación artificial, y la mortalidad por infecciones respiratorias de $0.4 \%$ en los primeros y de $48 \%$ en los segundos.

Es interesante notar que Woodbury, ${ }^{(11)}$ ya hacia 1922, había encontrado al estudiar 22.422 nacidos vivos en 8 ciudades norteamericanas que la mortalidad era mayor en los alimentados en forma artificial.

Robinson $^{(12)}$, estudiando 3.266 lactantes en Inglaterra hacia 1950, encuentra lo mismo. Posteriormente Sydow y Faxen $^{(13)}$ y también Mellander ${ }^{(14)}$ encontraron que la incidencia de infecciones agudas, otitis media, infecciones respiratorias altas y diarrea aguda era inferior en el lactante alimentado al pecho y señalan que aún es posible encontrar estas diferencias en grupos sociales con ambiente adecuado.

Puffer y Serrano(15) er su estudio "Patrones de Mortalidad en la Niñez", destacan el hecho que la mortalidad por diarrea es superior en áreas en que la lactancia materna es menos prevalente.

Referente a la situación chilena, Plank y Minalesi ${ }^{(16)}$, estudiando la relación existente. entre la mortalidad en el primer año de vida y el tipo de alimentación, encuentran que en el medio rural hay diferencias significativas en mortalidad infantil entre lactantes alimentados y no alimentados al pecho hasta los tres meses de edad. Así la mortalidad para los sobrevivientes es de $13.8 \%$ para los alimentados al pecho, y de $38.7 \%$ para los que sólo reciben mamaderas.

Recientemente Monckeberg y Marín ${ }^{(9,17,18)}$ han comentado en Chile sobre los extraordinarios avances que se han observado en la disminución de la mortalidad del preescolar, la que ha bajado a cifras de $2 \%$. Esto no se ha observado en igual forma con la mortalidad infantil, la que se mantiene a niveles altos. Sobre este mismo hecho comentan también autores extranjeros al referirse al caso chileno(17). Todos ellos insinúan que podría existir una relación entre la mortalidad infantil y la progresiva disminución de la lactancia materna.

¿Por qué se enferma y se muere menos ei lactante alimentado en forma natural?

La respuesta a esta pregunta encierra también la explicación del adecuado crecimiento y desarrollo del lactante alimentado en forma natural. Se considerarán en la respuesta los siguientes aspectos:

a) Relaciones entre lactancia materna $y$ estado nutritivo del lactante.

b) Relaciones entre lactancia materna $\mathrm{e}$ infecciones.

c) Relaciones entre lactancia materna y otros procesos mórbidos.

\section{LACTANCIA MATERNA Y ESTADO NUTRITIVO}

Jelliffe $\mathrm{e}^{(6)}$ ha comentado sobre el hecho que la leche es un producto biológico natural que tiene especificidad de especie. Así señala que diferentes especies tienen leche con diferentes concentraciones de proteínas y grasas, las que estarían relacionadas con la velocidad de crecimiento. Esto que según él es el producto de milenios de selección natural, se puede observar en el caso de la ballena, que viviendo en agua fría tiene leche con elevada concentración de grasas y alto poder calórico. La leche de conejo tiene un $14 \%$ de proteínas, ya que éste debe duplicar su peso en seis días. La leche humana, con sólo un $1.1 \%$ de proteínas, sería específica para los individuos de su especie que duplican su peso en 140 días.

La composición de la leche humana es significativamente diferente de la leche de vaca en numerosos componentes bioquímicos de importancia nutritiva. Jelliffe ${ }^{(6)}$ señala que ya se han descrito 100 de éstos. Los diferentes autores destacan algunos más que otros, pero es importante observar que el tema no está agotado.

Con el fin de resumir la importancia de algunos, señalaremos a continuación aspectos de aquellos componentes bioquímicos sobre los que se ha acumulado más información ${ }^{(6,19,3,5)}$ :

a) Proteinas y aminodicidos:

- La leche humana es rica en Cistina. El hígado del feto y del prematuro carecen de una enzima que les permite usar la metionina, que contiene en abundancia otras leches. Desde este punto de vista una leche rica en Cistina como la 
leche humana es más adecuada para el recién nacido, en especial si éste es prematuro ${ }^{(20,24)}$.

- La leche humana contiene un $1.1 \%$ de proteínas y de éstas una mayor proporción de lactoalbúmina que se absorbe mejor.

- Tanto el calostro coma la leche humana contienen nucleótidos específicos que son necesarios en la síntesis proteica.

b) Grasas:

- La leche humana tiene mayor contenido de ácidos grasos no saturados, los que son más adecuados para la alimentación humana de acuerdo a los estudios actuales en relación a prevención de arterosclerosis y enfermedad coronaria. Entre los ácidos grasos que contiene se encuentra el linoleico, que es considerado esencial y está presente en mayor concentración que en otras leches.

- Los monoglicéridos con ácidos grasos en posición 2 se absorben como tales desde el tubo digestivo. La leche humana tiene el ácido palmítico en posiciones 1 y 3 , por lo que para absorberlos debe ser liberado por la lipasa. Al ser liberado para su absorción precipita con el calcio en el lumen intestinal y es eliminado como jabón de palmitato de calcio por las deposiciones. Esto significa pérdida de calcio y grasa por la deposición.

- La leche humana contiene lipasa, enzima que actúa sobre las grasas, liberando los ácidos grasos para su absorción. Esta lipasa actúa en la leche humana aun en la etapa gástrica de la digestión, acelerando el proceso digestivo.

- La mielinización se completa en el sistema nervioso central hacia los tres años de vida. Para la mielinización se requieren grasas, probablemente específicas, en ciertas proporciones que estarian contenidas en forma más adecuada en la leche humana.

\section{c) Hidratos de Carbono:}

- La leche humana contiene una proporción mayor de lactosa que la leche de vaca, lo que representa un mayor aporte potencial de monosacáridos. Además, el exceso de lactosa contribuye a bajar el pH de la deposición, lo que podría ser importante en el tipo de flora intestinal que se desarrolla y también en hacer que el lactante a pecho tenga deposiciones más frecuentes y por lo tanto presente menor tendencia a la constipación.

- Las leches artificiales en general son preparadas con adición de sucrosa, lo que puede favorecer la obesidad infantil (21). Esta obesidad sería precursora de formas de obesidad del adulto de más difícil tratamiento. El exceso de sucrosa se asociaría además a la aparición de caries.

d) Minerales:

- El calcio y el fósforo se encuentran en una concentración menor, pero en una proporción más favorable (2.5 es a 1 ), lo que hace más rara la tetania neonatal.

- Aunque la concentración de fierro es más baja, su absorción es mejor que con leche de vaca.

- La leche humana contiene numerosos otros elementos como: manganeso, cobre, zinc, yodo, selenio. Se desconoce si alguno de éstos son o no esenciales. El zinc aparecería involucrado en la acrodermitis enteropática, dermitis periorificial, que aparece en algunos lactantes con ocasión del destete y que desaparece al reinstalarse la alimentación natural.

- Al tener un menor contenido de solutos (minerales y proteínas) la función renal aparece menos sobrecargada. El lactante alimentado en forma natural no requiere de aporte adicional de agua.

- La leche de vaca contiene en la actualidad una concentración mayor de sustancias radiactivas por efecto del paso de éstas a la leche luego de su ingestión y absorción junto con sus alimentos por parte de la vaca ${ }^{(22)}$.

\section{LACTANCIA MATERNA E INFECCIONES}

Anteriormente se citaron los autores que han estudiado la asociación global entre lactancia materna e infecciones. Los antecedentes acumulados se refieren a una menor incidencia global de infecciones tanto enterales como respiratorias. A propósito de las enterales se ha descrito como algo característico del lactante de numerosas culturas a la "diarrea del destete" $(6,27)$.

¿Cómo se explica esta asociación?

$\mathrm{Al}$ respecto hay dos aspectos a analizar:

a) ¿Tiene la leche humana propiedades antiinfecciosas especiales?

b) ¿Es la alimentación natural un mejor método de alimentación del lactante en un ambiente contaminado?

Se sintetizará a continuación la información reunida hasta el momento sobre el tema:

a) Propiedades antiinfecciosas de la leche humana:

1. Contenido de inmunoglobulinas: 
La leche humana y el calostro contienen inmunoglobulinas de todos los tipos (IgA, IgG, IgM, IgD, IgE). La más importante por su concentración y sus propiedades biológicas es la IgA.

La IgA y las otras inmunoglobulinas están presentes en el calostro inicial en concentraciones más altas que van disminuyendo en los días posteriores.

La presencia de inmunoglobulinas en el calostro no es sólo una característica de la especie humana. Brambell(23) se refiere al hecho de que los terneros y lechoncitos son agamaglobulinémicos al nacer, y reciben toda su protección inmunitaria inicial contenida en el calostro. Su tracto gastrointestinal es permeable a las proteínas sólo en el primer a segundo día de vida. Iyengar $^{(24)}$ sugiere que hay en el recién nacido posibilidad de absorber inmunoglobulinas en el intestino. En este sentido Walker y Hong ${ }^{(25)}$ señalan que la permeabilidad aumentada se debe a la imposibilidad de la mucosa intestinal de producir a su vez inmunoglobulina A secretora (SIgA) que la proteja contra la invasión de gérmenes o sustancias dañinas como antígenos.

Estos conocimientos están siendo empleados actualmente en unidades de prematuros y recién nacidos usando leche humana para controlar epidemias de diarrea. Así por ejemplo experiencias exitosas en este sentido son relatadas por Svirsky-Gross y Tassovatz ${ }^{(23)}$ en el extranjero y Zelada en nuestro medio ${ }^{(26)}$. Actualmente se está acumulando experiencia similar en la unidad de Recién Nacidos del Hospital Roberto del Río' 27 .

De acuerdo a diferentes trabajos citados por Goldman $^{(28)}$ la leche humana y el calostro contienen anticuerpos contra:

Clostridium Tetani
Bordetella Pertussis
Diplococcus Pneumoniae
Corynebacterium Diphteriae
Escherichia Coli
Salmonella
Shigella
Poliovirus 1, 2,3
Coxsackie virus B1, B5, B9
Echo Virus 6 y 9
Virus de la Influenza
humana:

2. Otros efectos protectores de la leche

\subsection{Factor Bifido:}

La leche humana contiene un factor que promueve el desarrollo de un bacilo aerobio no móvil especial: El Bacterium Bifidum o Lactobacillus Bifidus.

Mata $^{(29)}$ ha estudiado la variación de la flora intestinal desde el nacimiento hasta los 3 años de edad en una población Maya. En este grupo se ha observado que mientras los lactantes se alimentan en forma natural el $99 \%$ de la flora corresponde a bífido-bacterias. El menor que ha dejado de tomar pecho exhibe flora mixta: gram negativos y bífidobacterias.

De acuerdo a Mata ${ }^{(29)}$ el tracto gastrointestinal con un $\mathrm{pH}$ bajo, propio del lactante que recibe alimentación natural, es resistente a la instalación de otros gérmenes, incluyendo algunos patógenos como Shigella y algunos protozoos.

\subsection{Factor antiestafilococos:}

Este es un factor termoestable, no dializable, que reside en la fracción de ácidos grasos ${ }^{(29)}$. Este factor se ha visto que protege a animales experimentales contra la infección estafilocócica y podría estar relacionado con la resistencia a otras infecciones parenterales en la especie humana.

\subsection{Lactoferrina:}

La lactoferrina es una proteína especial que se liga al fierro e inhibe a estafilococos, escherichia coli y levaduras.

\subsection{Lizocima:}

Esta enzima, presente en la leche humana, tiene efectos anti entero bacterias y antigram positivos, y puede contribuir a la presencia de la flora bífida predominante al impedir la colonización del intestino por otros gérmenes ${ }^{(29)}$.

\subsection{Complemento:}

El componente $\mathrm{C}_{3}$ del complemento, presente en la leche humana, tiene efecto lítico sobre ciertas bacterias cuando éstas se fijan a anticuerpos.

\subsection{Células Inmunitarias:}

Smith, Goldman y Murillơ(30,31), citados por Mata $^{(29)}$, han encontrado un número significativo de linfocitos capaces de sintetizar IgA y también macrófagos con capacidad fagocitaria en el calostro.

b) En lo referente a si la alimentación natural es o no un mejor método de alimentación en un ambiente contaminado, hay autores que restan validez a todas las propiedades antiinfecciosas de la leche y señalan que la menor frecuencia de infecciones en el lactante alimentado al pecho sólo obedecería a una menor contaminación. La 
alimentación artificial del lactante en países con saneamiento inadecuado y bajo nivel cultural a una mayor trecuencia de infecciones enterales al disponerse del vehículo "Mamadera".

\section{LACTANCIA MATERNA Y OTROS PROCESOS MORBIDOS}

Se ha descrito una menor incidencia también en otros procesos mórbidos en los lactantes alimentados al pecho, la que no se explicaría en base a los elementos ya señalados, sino que se explicaría en base a participación de otros mecanismos etiopatogénicos, a saber:

\section{Otitis media aguda:}

$\mathrm{Su}$ incidencia es mayor en los lactantes que reciben mamadera ${ }^{(13,14)}$, ya que con frecuencia ésta es administrada con el lactante acostado en su cuna, lo que facilita el paso de leche al oído medio.

\section{Enfermedades alérgicas:}

Tanto las alergias cutáneas como las respiratorias han sido descritas como presentándose con una incidencia mayor en el lactante alimentado con mamadera con leche de vaca. Antígenos sensibilizantes, presentes en la leche de vaca, pasarían a través de la mucosa intestinal, incapaz de producir $\operatorname{SIgA}^{(25)}$. Gerrard ${ }^{(23)}$ recomienda por esta razón en forma especial la leche humana para lactantes con antecedentes alérgicos. Además, la administración de derivados del trigo, adicionados a la leche de vaca, está implicada en otras enfermedades alérgicas como la enfermedad celíaca ${ }^{(32)}$.

\section{Muerte por aspiracion:}

El riesgo de aspiración, y a consecuencia de ello asfixia y muerte, es mayor en la alimentación con mamadera y leche de vaca. La mayor digestibilidad de la leche humana facilita el vaciamiento gástrico ${ }^{(33)}$.

\section{Alteraciones del lenguaje:}

Broad $^{(34)}$ ha estudiado la claridad del lenguaje inglés en 134 niños de 5 y 6 años en Nueva Zelandia en forma retrospectiva y encuentra diferencias significativas en lo que a alimentación natural se refiere. El lenguaje es más claro en los que han recibido alimentación natural.

\section{LACTANCIA MATERNA Y AFECTIVIDAD}

La mayoría de los autores citados que se refieren al tema ${ }^{(5,6,22,33,35,36,37)}$ destacan las ventajas que para el desarrollo emocional tiene la alimentación natural al facilitar la relación estrecha y el mutuo intercambio afectivo entre la madre y su hijo. Se ha llegado a destacar como un elemento tan importante que se recomienda que los lactantes alimentados con mamadera la reciban simulando la posición cercana al seno materno de la alimentación natural.

Además de ser importante para el desarrollo emocional del lactante, indirectamente a través de este elemento las ventajas afectivas influyen sobre el crecimiento y desarrollo armónico del lactante. Como se ha demostrado a través de otros estudios, lactantes carentes de estimulación psicomotora $y$ afectiva pueden llegar a alterar su crecimiento a pesar de estar recibiendo aportes adecuados.

En resumen toda la información acumulada justifica plenamente el apelativo de "secreción viva" con que algunos autores se refieren a la leche humana administrada al pecho ${ }^{(6)}$.

Con todo el avance tecnológico en la industria de alimentos, aún es hoy válido lo dicho por Oliver Wendell Holmes, citado por Harfouche ${ }^{(5)}$ : "Los pechos maternos son más hábiles que el cerebro del sujeto más privilegiado en confeccionar la más óptima mezcla alimentaria".

En la presente revisión no se han mencionado algunas ventajas adicionales de la lactancia natural y que se refieren a las ventajas que para la madre representa la alimentación natural y asimismo las ventajas económicas.

En lo referente a ventajas para la madre se ha señalado que la lactancia natural representa un método de control de fertilidad natural, además acelera la involución a su estado intergestacional del útero materno a través de los efectos hormonales de las mismas hormonas que participan en el proceso de lactancia, ayuda a la resolución de los depósitos grasos establecidos durante el embarazo y contribuye a producir un estado de mayor satisfacción personal al permitir el desempeño total del rol materna ${ }^{55,22,33,38)}$.

En cuanto a ventajas económicas se ha destacado el hecho de que el costo de la alimentación natural es inferior al de la alimentación artificial ${ }^{399}$. Hay autores que destacan el que en un mundo con dificultades en la producción proteica se esté dejando sin desarrollar el potencial que representa la producciórr de proteína de alto valor biológico durante la lactancia natural ${ }^{(6)}$. 


\section{REFERENCIAS}

1 Patri, A., Sepúlveda, H.: "Evolución de la lactancia materna", Jornadas de Lactancia Materna del Area Hospitalaria Norte de Santiago, 1977.

2 Margozzini, J.: "Característica de la alimentación del lactante eutrófico en el Area Norte de Santiago y sus relaciones con algunas variables socioeconómicas". Rev. Chil. Pediat. 43: 57, 1972.

3 Oseid, B. J. "Breast-Feeding and Infant Health". Clinical Obstetrics and Gynecology, 18: 149, 1975.

4 Valiente, S., Concha, C., Pacheco, E., Valenzuela, M. A., Castro, N., Boj, M. T. Estudio de la desnutrición infantil de un centro pediátrico de Quinta Normal. II Parte: "Factores condicionantes de la desnutrición infantil", Departamento de Nutrición. Facultad de Medicina, Sede Norte, Publ. Inv. 10/70, Universidad de Chile.

5 Harfouche, J.K. "The Importance of Breast-Feeding". The Journal of Tropical Pediatrics 16: 135, 1970.

6 Jelliffe, D.B., Jelliffe, E.F.P. (Editors) "The Uniqueness of Human Milk". American Journal of Clinical Nutrition 24: $968,1971$.

7 Monckeberg, F. y cols. "Estudio del estado nutritivo y de las condiciones de vida de la población infantil de la provincia de Curico". Rev. Chil. Pediat. 37: 491, 1967.

8 Arteaga, A., Lacassie, I., Castro, $\dot{N}$. "Estudio de la alimentación y del estado nutritivo de la población indigena de la precordillera de Arica", Chile. Rev. Chil. Pediat. 37: 491, 1967.

9 Monckeberg, F. "Lactancia materna corta: alto riesgo en paises subdesarrollados". Apartado Dacente 3/76 Departamento de Nutrición y Tecnología de Alimentos.

${ }^{10}$ Grulee, C. G., Sanford, H. N., Herron, P.A. "Breast and Artificial Feeding". J.A.M.A. 103: 735, 1934.

11 Woodbury, R.M. "The relation between breast and artificial feeding and Infant Mortality". Amer. J. Hygiene, 2: 668, 1922.

12 Robinson, M. "Infant Morbidity and Mortality, a study of 3.266 infants". Lancet 260: 788, 1951.

${ }^{13}$ Sydow, G., Faxen, N. "Breast or cow's milk as infant food". Acta Pediat. 43: 362, 1954.

14 Mellander, O., Vahiquist, B., Mellkin, T. "Breast feeding and artificial feeding", Acta Pediat. 48 (Suppl. 116): 1, 1973.

15 Puffer, R. R., Serrano, C. V. "Patterns of Mortality in Childhood". Scient. Pu. N.o 262, Pan American Health Organization W. H. D. 1973.

16 Plank, SJ., Milanesi, M.L. "Infant feeding and Infant Mortality in Rural Chile", Bull WAO 48: 203, 1973.

17 Marin, P. "Lactancia Natural: Desafio en la enfermedad, desnutrición y mortalidad infantil". Kev. Chil. Pediat. 45: $259,1974$.

18 Marin, P. "Lactancia Materna". Rev. Chil. Pediat. 46: 378, 1975.
19 Gyorgy, P. "Biochemical Aspects". American Journal of Clinical Nutrition 24: 970, 1971.

20 Räihä, N.C.R. "Biochemical Basis Nutritional Management of preterm Infants". Pediatrics 53: 147, 1974.

21 Jelliffe, D.B. Jelliffe E.F.P. "Fact Babies: Prevalence, Perils and Prevention". Environmental Child Health 21: 123, 1975.

22 Fowler, M. “A New Era in Breast Feeding", Environmental Child Health 22: 34, 1976.

23 Gerrard, John W. "Breast Feeding: Second Thoughts". Pediatrics 54: 757, 1974.

24 Iyengar, L., Selvaraj, R.J. "Intestinal Absorption of Immunoglobulins by Newborn Infants”, Arch. Dis. Child. 47: $411,1972$.

25 Walker, W.A., Hong, $R$. "Immunology of the Gastrointestinal Tract. Part. I". J. Pediatr. 83: 517, 1973.

${ }^{26}$ Zelada, V. Comunicación a las Jomadas de Lactancia Materna Area Hospitalaria Poniente. Servicio Nacional de Salud, 1976.

27 Rizzardini, M. Video Tape presentado a Jornadas de Lactancia Matema del Area Hospitalaria Norte de Santiago, 1977.

28 Goldman, A. S., Smith, C. W. "Host Fesistance Factors in Human Milk". J. Pediatr. 82: 1082, 1973.

29 Mata, L. J., Eyatt, R. G. "Host Resistance to Infection". American Journal of Clinical Nutrition 24: 976, 1971.

$30 \mathrm{Smith}, \mathrm{C}$. W., Goldman, A.S. "The Cells of Human Colostrum, I. In Vitro Studies of Morphology and Functions", Pediat. Res. 2: 103, 1968.

31 Murillo, G. J., Goldman, A. S. "The Cells of Human Colostrum, II. Synthesis of IgA and BIC", Pediat. Res. 4: 71, 1970.

32 Anderson, C. M., Gracey, M., Burke, V. "Coeliac Disease". Arch. Dis. Child. 47: 292, 1972.

33 Jimenez, J. "Lactancia Materna". CONPAN, 1976.

34 Broad, F. E. "The effects of infant feeding on speech quality". N.Z. Med. J. 76: 482, 1972.

35 Newton, N. "Psychologic differences between breast and bottle feeding". American Joumal of Clinical Nutrition 24: 993,1971

${ }^{36}$ Lubchenco, L. O. "Infant Feeding", en KEMPE, C. H., Silver, H. K., O'Brien, D. "Current Pediatric Diagnosis and Treatment”. Lange Medical Publications, California, 1974.

${ }^{37}$ Ministerio de Salud, "Componente educativo en lactancia materna integrado a los programas de salud Materno-Infantil". MINISTERIO DE SALUD PUBLICA, Santiago, Chile, 1976.

38 Jelliffe, D.B., Jelliffe, E.F.P. "Lactation, conception, and the nutrition for the nursing mother and child". J. Pediatr. 81: $829,1972$.

39 Mc Kigney, J. "Economic Aspects". American Journal of Clinical Nutrition 24: 1005, 1971.

40 Workshop: "Human Milk in Premature Infant Feeding". Pediatrics 57: 741, 1976. 